\title{
Correction to: Removal of Tin from Extreme Ultraviolet Collector Optics by In-Situ Hydrogen Plasma Etching
}

\author{
Daniel T. Elg ${ }^{1,4,5} \cdot$ Gianluca A. Panici $^{1}$ Sumeng Liu ${ }^{2}$ • \\ Gregory Girolami ${ }^{2} \cdot$ Shailendra N. Srivastava $^{3} \cdot$ David N. Ruzic $^{1}$
}

Published online: 3 April 2018

(C) Springer Science+Business Media, LLC, part of Springer Nature 2018

\section{Correction to: Plasma Chem Plasma Process (2018) 38:223-245 https://doi.org/10.1007/s11090-017-9852-4}

The original version of this article unfortunately contained a mistake in the "Deposition of Stannane (DOS) Chamber" section. It should read as follows: "The synthesis of stannane was accidentally stated to follow an earlier version of the procedure that was more similar to that published by Norman [22]. This procedure was eventually modified by replacing the diethyl ether solvent with a high-boiling solvent mixture so that trap-to-trap distillations could be omitted without contamination of the final product. A 500-mL three-neck flask was equipped with a magnetic stir bar, and its joints were fitted with a dry ice condenser, a connection to a Schlenk line, and a rubber septum. The hose adapter on the top of the dry

The original article can be found online at https://doi.org/10.1007/s11090-017-9852-4.

Daniel T. Elg

daniel.elg@berkeley.edu

$\bowtie$ David N. Ruzic

druzic@illinois.edu

1 Department of Nuclear, Plasma, and Radiological Engineering, Center for Plasma-Material Interactions, University of Illinois at Urbana-Champaign, 216 Talbot Laboratory MC-234, $104 \mathrm{~S}$. Wright St, Urbana, IL 61801, USA

2 Department of Chemistry, University of Illinois at Urbana-Champaign, 505 S. Matthews Ave., 104 S. Wright St, Urbana, IL 61801, USA

3 Applied Research Institute, University of Illinois at Urbana-Champaign, 2100 S. Oak St. Suite 206, Champaign, IL 61820, USA

4 Present Address: Department of Chemical and Biomolecular Engineering, University of California, Berkeley, 201 Gilman Hall, Berkeley, CA 94720, USA

5 Applied Materials, Inc., 3050 Bowers Ave, PO Box 58039, Santa Clara, CA 95054, USA 
ice condenser was connected through three U-shaped traps in sequence to the Schlenk line. The traps were equipped with stopcocks on both their inlets and outlets. The entire system was evacuated and refilled with $\mathrm{N}_{2}$ three times. The traps were evacuated and were isolated by closing their stopcocks. The flask was charged with $\mathrm{LiAlH}_{4}(2.16 \mathrm{~g}, 57 \mathrm{mmol}), 1,2-$ dimethoxyethane $(30 \mathrm{~mL})$, and dibutyl ether $(30 \mathrm{~mL})$. We found that this solvent mixture worked far better than either solvent alone. The mixture was cooled to $-196{ }^{\circ} \mathrm{C}$, the condenser was charged with dry ice, the trap nearest to the flask was cooled to $-95{ }^{\circ} \mathrm{C}$ (toluene slush), and the remaining two traps were cooled to $-196{ }^{\circ} \mathrm{C} . \mathrm{SnCl}_{4}(6.0 \mathrm{~mL}$, $51 \mathrm{mmol}$ ) was added slowly to the flask through the septum by means of a syringe equipped with a Teflon needle. The septum was replaced with a glass stopper, and the flask was evacuated. The flask was then isolated from the Schlenk line, and the reaction mixture was slowly warmed to $-50{ }^{\circ} \mathrm{C}$ to allow the solvent to melt. The stopcocks on the traps were then opened except for the stopcock between the last trap and the Schlenk line, which was closed most of the time but opened every $5 \mathrm{~min}$ or so as to remove the generated $\mathrm{H}_{2}$. The reaction mixture was slowly warmed to $-30{ }^{\circ} \mathrm{C}$ and was kept at this temperature for $2 \mathrm{~h}$. At the end of this period, the material in the $-95^{\circ} \mathrm{C}$ trap (mostly solvent) was discarded. The stannane in the $-196{ }^{\circ} \mathrm{C}$ traps was combined and stored in liquid nitrogen until used. NMR studies show that only traces of solvent $(<0.1 \%)$ are present in the stannane product". 